\title{
Air-steam gasification of sewage sludge in a fluidized bed. Influence of some operating conditions.
}

\author{
N. Gil-Lalaguna *, J. L. Sánchez, M. B. Murillo, E. Rodríguez, G. Gea \\ Thermo-chemical Processes Group, Aragón Institute of Engineering Research (I3A), Universidad de \\ Zaragoza, c/ Mariano Esquillor s/n., 50018, Zaragoza, Spain. \\ * Corresponding Author Tel: $\quad$ T34976762224 e-mail: noemigil@unizar.es
}

\begin{abstract}
An experimental work was carried out to investigate the viability of energy recovery from the air-steam gasification of sewage sludge. The relative influence of different factors, as well as the effect of their possible interactions, has been determined by means of analysis of variance. Temperature was found to be the most influential factor for most of the variables analyzed. Solid yield (35-41 wt. \%) and tar content (11-45 $\left.\mathrm{g} / \mathrm{m}^{3}{ }_{\text {STP}}\right)$ were largely reduced with temperature, whereas gas production $(0.89-1.32$ $\mathrm{m}_{\mathrm{STP}}^{3} / \mathrm{kg}$ sewage sludge dry and ash free), carbon yield to gas phase (62-90 wt. \%), gasification efficiency (39-66 \%), and $\mathrm{H}_{2}$ and $\mathrm{CO}$ yields $(20-52$ and $137-414 \mathrm{~g} / \mathrm{kg}$ sewage sludge dry and ash free, respectively) were improved at high temperature. Other important parameters for the end-use of the gas such as its heating value (4.12-6.20 $\mathrm{MJ} / \mathrm{m}^{3}{ }_{\text {STP }}$ ) and its $\mathrm{H}_{2} / \mathrm{CO}$ molar ratio (1.46-3.25) were greatly influenced by the composition of the gasification medium, since the increase in the steam to oxygen ratio was favourable for both. The comparison of experimental and theoretical results highlights that equilibrium was not reached during the experimental runs.
\end{abstract}

Keywords: air-steam gasification; sewage sludge; fluidized bed. 


\section{Introduction}

Biomass is one of the most important primary renewable energy sources. The conversion of biomass to energy encompasses a wide range of materials, conversion technologies and end-use applications of the products, such as power/heat generation, transportation fuels and chemical feedstocks. Sewage sludge, which is the waste produced by wastewater treatment processes, can be considered an important renewable biomass energy source [1].

As a result of the application of the Urban Wastewater Treatment Directive (UWWTD) 91/271/EEC [2], new municipal wastewater treatment strategies have been developed during the last two decades in order to improve the quality of effluents. Existing treatment plants have been upgraded and new and more effective treatment plants have been designed and implemented. In parallel to the improvement of the effluent quality, environmental awareness about sewage sludge management has gained strength. The main commercial means of sewage sludge disposal include its use as fertilizer, land filling or incineration [3, 4]. However, because of increasing legal limitations on sewage sludge land filling and agricultural reuse, energy recovery from sewage sludge remains an attractive and sustainable way of management. Thermal processes such as pyrolysis, gasification or combustion of sewage sludge have thus attracted considerable scientific interest. This paper presents an experimental work on sewage sludge gasification.

Gasification is the conversion of a carbonaceous material into a gas fuel by heating it in a gasification medium such as air, oxygen or steam. Gas from gasification consists of a mixture of carbon monoxide, carbon dioxide, hydrogen, methane and other light hydrocarbons, nitrogen (if air is used as gasifying agent) and steam. This gas can be used to power gas engines and gas turbines or used as a chemical feedstock to produce 
liquid fuels [5]. During gasification, a mixture of heavy and condensable hydrocarbons (tars) is also produced. The presence of tar in the gas causes problems associated with condensation, formation of aerosols and polymerization leading to more complex structures which limit the subsequent utilization of the gas.

Operating conditions during gasification (such as the nature of the biomass, pressure, temperature, residence time or gasification medium) play an important role in both tar formation and gas quality. The higher the temperature, the lower the tar content in the product gas [6], but other factors such as the risk of ash sintering limit the operating temperature. The use of different gasifying agents such as air, steam, steamoxygen mixtures or carbon dioxide has been reported in the literature. Both gas composition and gas heating value are noticeably affected by the gasification medium because of the variation of selectivity in the gasification reactions [7]. Generally, steam gasification enhances $\mathrm{H}_{2}$ production compared to air gasification, and also leads to a higher gas heating value because the dilution of the gas with nitrogen is avoided [8]. However, the steam gasification reactions are endothermic and require a continuous supply of energy. Given this background, biomass gasification with mixtures of air and steam appears to be a potential solution from the economic point of view, since the partial combustion of biomass inside the gasifier can supply the required energy for the process, turning it into an autothermal process. The improvement in gas quality by feeding a flow of steam together with the air stream during biomass gasification has been reported in several experimental studies [9-12].

In the particular case of sewage sludge, experimental studies based on air gasification [13-17] and steam gasification [18] have been reported in the literature. In general, the gas composition and the gas heating value from sewage sludge gasification are close to typical values obtained from other kinds of biomass, which demonstrates 
the potential of sewage sludge as a raw material for the gasification process. However, tar formation and other additional problems such as the formation of other pollutants $\left(\mathrm{H}_{2} \mathrm{~S}, \mathrm{HCl}\right.$ or $\left.\mathrm{NH}_{3}\right)$ hinder the development of sewage sludge gasification, so new efforts are required in order to optimize the process.

In this work, an experimental study (based on a $2^{\mathrm{k}}$ factorial design) on sewage sludge gasification in a fluidized bed with mixtures of air and steam has been developed in order to find out the influence of several operating conditions (temperature, composition of the gasification medium and gasifying agent to biomass ratio) on the gasification performance. Furthermore, experimental results have been compared with theoretical data which were determined considering equilibrium conditions.

\section{Materials and methods}

\subsection{Sewage sludge}

Anaerobically digested and thermally dried sewage sludge (SS) was supplied by a Spanish urban wastewater treatment plant. Feedstock analyses were performed at the Instituto de Carboquímica (ICB-CSIC) in Zaragoza (Spain) according to standard methods: moisture according to ISO-589-1981, ash according to ISO-1171-1976, volatiles according to ISO-5623-1974, ultimate analysis (CHNS) using a Carlo Erba 1108 and heating value according to ISO-1928-89 (Table 1). More details about the sewage sludge characterization, such as FTIR and X-ray diffraction analyses, can be found elsewhere [19]. Sewage sludge was smashed and sieved to obtain a feed sample in the size range of $250-500 \mu \mathrm{m}$.

\subsection{Experimental setup}

Sewage sludge gasification runs have been carried out in a laboratory-scale fluidized bed reactor operating at atmospheric pressure, with continuous feed of solid and 
continuous removal of ash. The gasifier was a tubular reactor made of refractory steel (AISI 310) divided into two parts: a bed zone, with an inner diameter of $40 \mathrm{~mm}$, and a freeboard zone, with an inner diameter of $63 \mathrm{~mm}$. Sewage sludge was continuously fed to the reactor by a feeding system composed of a screw-feeder and a variable speed motor. The solid feed rate in each experiment was around $2.1 \mathrm{~g} / \mathrm{min}$. Ash from previous sewage sludge gasification tests constituted the solid bed by itself from the beginning of the runs. When the amount of bed material inside the reactor exceeded the height of the bed zone, it left the reactor by overflow through a lateral pipe and was collected in a separate vessel. The reactor was heated by an electrical furnace with three different heating zones (bed, free-board and cyclone), which could be controlled independently. The bed temperature was one of the factors under study, ranging between 770 and 850 ${ }^{\circ} \mathrm{C}$ (the same as in the free-board), while the cyclone temperature was set at $450{ }^{\circ} \mathrm{C}$. A schematic diagram of the experimental setup can be found elsewhere [20].

The gasifying/fluidizing agent used in the process consisted of different mixtures of steam and enriched air (air + oxygen). Furthermore, an additional flow of nitrogen was necessary in two of the experiments (those with the lowest air requirement) in order to avoid differences in the dilution effect of the gas with nitrogen and in the fluidization rate (which was around 5-7 times greater than the minimum fluidization rate). The feed rate of these gases (air, oxygen and nitrogen) was adjusted by using mass flow controllers. The water was fed through a HPLC pump and vaporized before mixing into the gas stream. The composition and the amount of gasifying agent were the other factors under study in this work. The mixture of oxygen, steam and approximately $2 / 3$ of the total air required was fed into the fluidized bed reactor through its distribution plate, while the remaining air was fed with the solid to facilitate its movement through 
the feeding pipe, which was externally refrigerated to prevent reactions taking place outside the bed.

The vapors and gases produced during gasification remained inside the reactor between 7 and 8 seconds and then passed through a cyclone and a hot filter, both at 450 ${ }^{\circ} \mathrm{C}$, in which the solid particles swept by the gas were collected. Next, the gases and vapors passed through two ice-cooled condensers, where water and condensable organic compounds (tar) were collected. A cotton filter was situated after the condensers in order to remove small particulates and aerosols swept by the gas. The volume of particle- and tar-free gas was measured by a volumetric meter and its composition was analyzed on line using a micro gas chromatograph (Agilent 3000-A), which determined the volume percentages of $\mathrm{H}_{2}, \mathrm{O}_{2}, \mathrm{CO}, \mathrm{CO}_{2}, \mathrm{CH}_{4}, \mathrm{C}_{2} \mathrm{H}_{4}, \mathrm{C}_{2} \mathrm{H}_{6}, \mathrm{C}_{2} \mathrm{H}_{2}$ and $\mathrm{H}_{2} \mathrm{~S}$. Water content in the condensed fraction was analyzed off line by Karl Fischer titration (so the amount of tar was determined by difference) and the tar composition was analyzed by gas chromatography with mass spectroscopy and flame ionisation detectors (MS/FID GC). The experiments were carried out during $90 \mathrm{~min}$ to ensure that the stationary state was reached [21].

\subsection{Experimental design and data analysis}

The influence of three operating factors (temperature, gasifying agent to biomass ratio and composition of the gasification medium) on sewage sludge gasification performance has been studied experimentally by means of a $2^{\mathrm{k}}$ factorial design, where $\mathrm{k}$ indicates the number of factors studied (in this case 3 ) and $2^{\mathrm{k}}$ represents the number of runs (in this case 8). Furthermore, three replicates at the center point (CP) were carried out in order to evaluate both the experimental error and the curvature shown by the evolution of each response variable, that is to say, whether this evolution is linear or not within the experimental range studied. This experimental design is suitable not only for 
studying the influence of operating conditions, but also the influence of their possible interactions. An interaction occurs when a factor influences a response variable in a different way depending on the value of another factor.

The three analyzed factors were: (i) bed reactor temperature (which ranges between 770 and $850{ }^{\circ} \mathrm{C}$ ); (ii) gasifying ratio (GR) between the mass flow of gasifying agent (oxygen plus steam) and the mass flow of dry and ash-free basis (daf) sewage sludge (which ranges between 0.8 and $1.1 \mathrm{~g} / \mathrm{g} \mathrm{SS}$ daf); (iii) nature of the gasification medium, represented by the $\mathrm{H}_{2} \mathrm{O} / \mathrm{O}_{2}$ molar ratio (which ranges between 1 and 3). The overall flow rate of gasifying agent was kept constant when the $\mathrm{H}_{2} \mathrm{O} / \mathrm{O}_{2}$ molar ratio was modified. These three factors together with their respective ranges of study were chosen on the basis of works of other authors concerning gasification of different kinds of biomass in fluidized bed reactors [9-12].

As can be seen in Table 2, the experimental design consists of 8 runs plus 3 replicates at the center point $\left(810^{\circ} \mathrm{C}, 0.95 \mathrm{~g} / \mathrm{g} \mathrm{SS}\right.$ daf, $\left.2 \mathrm{~mol} \mathrm{H}_{2} \mathrm{O} / \mathrm{mol} \mathrm{O}_{2}\right)$. As usually occurs when an experimental design is planned, the lower and upper limits of the factors are coded as -1 (in this case $\mathrm{T}=770{ }^{\circ} \mathrm{C}, \mathrm{GR}=0.8$ and $\mathrm{H}_{2} \mathrm{O} / \mathrm{O}_{2}=1$ ) and 1 (in this case $\mathrm{T}=850{ }^{\circ} \mathrm{C}, \mathrm{GR}=1.1$ and $\mathrm{H}_{2} \mathrm{O} / \mathrm{O}_{2}=3$ ), respectively. The use of coded levels enables an easy identification of the term with the greatest influence on the response variable: the higher the coefficient, the more influential the factor.

The response variables analyzed were: (i) distribution of products (yields to the different gasification products: solid, gas and tar); (ii) gas composition, determined on line using a micro gas chromatograph; (iii) production of each gaseous component; (iv) lower heating value of the product gas $\left(\mathrm{LHV}_{\text {gas }}\right)$; (v) cold gasification efficiency; (vi) carbon yield to gas phase and (vii) tar composition. 
Statistical analyses of the results have been carried out by analysis of variance (ANOVA), using the Design-Expert ${ }^{\circledR} 7$ software (from Stat-Ease, Inc). ANOVA analysis evaluates whether the effect of the factors, the interactions between them and the curvature have a significant influence or not on the response variables. A confidence level of $95 \%$ for the F-distribution was selected to determine the significant effects.

\section{Results and discussion}

\subsection{Distribution of products}

Experimental results for the distribution of products are presented in Table 3.

Furthermore, as a result of the ANOVA analysis, Table 4 shows the relative influence of each factor on the product distribution. In this table, the average data represent the average of the whole set of results obtained for each response variable, the coefficients associated to the different factors ( $T$, GR and $\mathrm{H}_{2} \mathrm{O} / \mathrm{O}_{2}$ ) show how the response variables evolve when varying each factor (considering the coded values for the factors within the studied range), and the coefficients associated to the interactions show whether a factor influences a response variable in a different way depending on the value of another factor.

\subsubsection{Solid yield and carbon content in the solid}

The solid yield is defined as the mass ( $\mathrm{g}$ ) of solid product collected per $100 \mathrm{~g}$ of sewage sludge fed. Because of the high ash content in the sewage sludge (39 wt. \%), the solid residue is an important by-product in its gasification process and its yield varied between 35 and 41 wt. \%, whilst typical values for other kinds of biomass such as wood or straw are below 8 wt. \% [22].

Carbon content in the solid product was analyzed using a Leco TruSpec Micro Elemental Analyzer (Table 3). According to the ANOVA results (Table 4), carbon 
content in the solid product is reduced by increasing both the gasification temperature (higher reaction rate) and the gasifying ratio, and by decreasing the $\mathrm{H}_{2} \mathrm{O} / \mathrm{O}_{2}$ ratio (Fig. 1), which seems to indicate that carbon oxidation is faster than its steam gasification. Although temperature is the most influential factor for the carbon reaction, its effect depends on other operating conditions, since its interaction with the $\mathrm{H}_{2} \mathrm{O} / \mathrm{O}_{2}$ ratio is a significant term (Fig. 1a). This fact shows that carbon reactions with oxygen are more sensitive to temperature changes that the reactions with steam.

The results of the solid yield together with those of the carbon content in the solid (Table 3) suggest that inorganic ash compounds could have been released to the gas phase during the gasification process, since some data of solid yield are even below the original ash content of the sewage sludge (39 wt. \%). Both the transformation and the release to gas phase of ash compounds during thermo-chemical processes have been shown in other studies $[23,24]$, although this was usually found to take place at higher temperatures.

\subsubsection{Gas yield}

The gas yield is defined as the volume of gas produced $\left(\mathrm{m}^{3}{ }_{\text {STP }} \mathrm{N}_{2}\right.$-free basis, where STP means standard conditions of temperature and pressure at $0^{\circ} \mathrm{C}$ and 1 atm) per kilogram of SS $d a f$ fed. The gas yield data from the sewage sludge gasification varied between 0.89 and $1.32 \mathrm{~m}^{3}{ }_{\mathrm{STP}} / \mathrm{kg}$ SS $d a f$, so these values are close to the typical ones found in the literature for similar operating conditions and different kinds of biomass [7, $9,12]$.

The ANOVA analysis (Table 4) shows that the gas yield does not follow a linear response within the studied range of the factors, since the curvature is a significant term. Temperature is clearly the most influential factor for the production of gas. The significant increase of the gas yield with temperature may be due to different processes 
that are favored by higher temperatures: greater production of gas in the initial stage of pyrolysis, cracking and steam reforming of tars and endothermic reactions of char gasification [12]. The increase of GR also favors the production of gas, although its effect is less significant than that corresponding to temperature. Significant interactions of temperature with both the GR and the $\mathrm{H}_{2} \mathrm{O} / \mathrm{O}_{2}$ ratio have been found: the effect of temperature on the gas yield is intensified at the highest value of the GR (Fig. 2a) and at the lowest $\mathrm{H}_{2} \mathrm{O} / \mathrm{O}_{2}$ ratio (Fig. 2b).

\subsubsection{Tar content in the product gas}

The tar content is defined as the mass $(\mathrm{g})$ of condensable organic compounds collected in each experiment per $\mathrm{m}^{3}$ STP of dried gas measured after condensing the vapors. The lowest values of tar content obtained in this work are close to the typical values found for fluidized bed biomass gasifiers which, according to Corella et al. [25], usually range between 8 and $15 \mathrm{~g} / \mathrm{m}^{3}$ STP.

As occurred with the gas yield, the tar content in the gas does not follow a linear response within the studied range of the factors, as the curvature is a significant term. Temperature is also the most influential factor for tar content (Table 4). The rise in the gasification temperature from 770 to $850{ }^{\circ} \mathrm{C}$ causes a clear reduction in tar formation (Fig. 3a) because of the enhancement of tar cracking and reforming reactions [6]. The tar content is also reduced by decreasing the $\mathrm{H}_{2} \mathrm{O} / \mathrm{O}_{2}$ ratio in the gasification medium, suggesting that tar combustion reactions are faster than tar steam reforming, and by increasing the GR, although the effect of the latter factor is less significant. The influence of the GR on the tar content disappears when working at the highest temperature (Fig. 3a) or at the highest $\mathrm{H}_{2} \mathrm{O} / \mathrm{O}_{2}$ ratio (Fig. 3b).

\subsection{Gas composition}


The gas composition from a gasification process is the result of many complex and competing reactions. The most representative of these reactions are given below:

$\begin{array}{llr}\text { Oxidation } & \mathrm{C}+\mathrm{O}_{2} \leftrightarrow \mathrm{CO}_{2} & \Delta \mathrm{H}<0 \\ \text { Partial oxidation } & \mathrm{C}+1 / 2 \mathrm{O}_{2} \leftrightarrow \mathrm{CO} & \Delta \mathrm{H}<0 \\ \text { Boudouard } & \mathrm{C}+\mathrm{CO}_{2} \leftrightarrow 2 \mathrm{CO} & \Delta \mathrm{H}>0 \\ \text { Water-gas primary } & \mathrm{C}+\mathrm{H}_{2} \mathrm{O} \leftrightarrow \mathrm{CO}+\mathrm{H}_{2} & \Delta \mathrm{H}>0 \\ \text { Water-gas secondary } & \mathrm{C}+2 \mathrm{H}_{2} \mathrm{O} \leftrightarrow \mathrm{CO}_{2}+2 \mathrm{H}_{2} & \Delta \mathrm{H}>0 \\ \text { Water-gas shift (WGS) } & \mathrm{CO}+\mathrm{H}_{2} \mathrm{O} \leftrightarrow \mathrm{CO}_{2}+\mathrm{H}_{2} & \Delta \mathrm{H}<0 \\ \text { Methanation } & \mathrm{C}+2 \mathrm{H}_{2} \leftrightarrow \mathrm{CH}_{4} & \Delta \mathrm{H}<0 \\ \text { Steam reforming } & \mathrm{C}_{\mathrm{n}} \mathrm{H}_{\mathrm{x}}+\mathrm{nH}_{2} \mathrm{O} \leftrightarrow \mathrm{nCO}+(\mathrm{x} / 2+\mathrm{n}) \mathrm{H}_{2} & \Delta \mathrm{H}>0 \\ \text { Dry reforming } & \mathrm{C}_{\mathrm{n}} \mathrm{H}_{\mathrm{x}}+\mathrm{nCO}_{2} \leftrightarrow 2 \mathrm{nCO}+(\mathrm{x} / 2) \mathrm{H}_{2} & \Delta \mathrm{H}>0 \\ \text { Cracking } & \mathrm{C}_{\mathrm{n}} \mathrm{H}_{\mathrm{x}} \leftrightarrow \mathrm{C}+(\mathrm{x} / 2) \mathrm{H}_{2} & \Delta \mathrm{H}>0\end{array}$

As usual in a biomass gasification process, the main gases produced during sewage sludge gasification are $\mathrm{H}_{2}, \mathrm{CO}, \mathrm{CO}_{2}$ and light hydrocarbons, $\mathrm{CH}_{4}$ being the most abundant of them. In addition, $\mathrm{H}_{2} \mathrm{~S}$ is also released during the process due to the presence of sulfur-compounds in the sewage sludge (Table 1). Statistical analyses of gas composition have not been included in this work because it was considered preferable to analyze the production or the specific yield of each gaseous compound ( $\mathrm{g} / \mathrm{kg} \mathrm{SS} d a f)$, as detailed in the next section.

The average gas composition (dry basis) obtained in each experiment is reported in Table 3. Considerable differences in the fractions of the gaseous compounds have been found. For example, $\mathrm{H}_{2}$ (11.0-25.1 vol. \%), $\mathrm{CO}$ (5.7-14.1 vol. \%), $\mathrm{CO}_{2}$ (12.6-23.8 vol. \%) or $\mathrm{CH}_{4}$ (2.6-4.1 vol. \%) can double or halve their percentages depending on the operating conditions. These volume percentages lead to $\mathrm{H}_{2} / \mathrm{CO}$ and $\mathrm{CO} / \mathrm{CO}_{2}$ molar ratios in the exit gas ranging from $1.46-3.25$ and $0.29-0.88$, respectively. The $\mathrm{H}_{2} / \mathrm{CO}$ 
molar ratio is an important parameter in view of possible end uses of the gas, and values close to 2 are usually required in processes such as methanol or Fischer Tropsch synthesis [26]. According to the ANOVA results (Table 4), the composition of the gasification medium is clearly the most influential factor for this ratio. The higher the $\mathrm{H}_{2} \mathrm{O} / \mathrm{O}_{2}$ ratio used as gasifying agent, the higher the $\mathrm{H}_{2} / \mathrm{CO}$ molar ratio obtained in the gas product. Working at lower temperatures also leads to an increase in the $\mathrm{H}_{2} / \mathrm{CO}$ molar ratio.

The $\mathrm{CO} / \mathrm{CO}_{2}$ ratio shows how the carbon initially contained in the sewage sludge is distributed among both compounds. The higher the gasification temperature, the higher the $\mathrm{CO} / \mathrm{CO}_{2}$ ratio obtained in the product gas. Furthermore, the GR exerts a negative influence on the $\mathrm{CO} / \mathrm{CO}_{2}$ ratio, although its effect is less significant than that of the temperature.

\subsection{Production of each gaseous compound}

The production or yield of each analyzed gas $\left(\mathrm{H}_{2}, \mathrm{CO}, \mathrm{CO}_{2}, \mathrm{CH}_{4}, \mathrm{C}_{2} \mathrm{H}_{\mathrm{x}}\right.$ and $\left.\mathrm{H}_{2} \mathrm{~S}\right)$ is defined as the mass ( $\mathrm{g}$ ) of each gas produced per kilogram of SS daf fed.

Both experimental and theoretical yields of gases are analyzed in this section. The theoretical production of each gas during sewage sludge gasification at equilibrium conditions has been determined using HSC Chemistry ${ }^{\circledR} 6.1$ software, simulating the same operating conditions that had been previously tested in the laboratory, that is, following the same $2^{\mathrm{k}}$ factorial design. According to the theoretical results obtained, the gas product from sewage sludge gasification at equilibrium conditions should only contain $\mathrm{H}_{2}, \mathrm{CO}, \mathrm{CO}_{2}, \mathrm{CH}_{4}, \mathrm{H}_{2} \mathrm{~S}$ and $\mathrm{NH}_{3}$.

The experimental and the theoretical yields of gases are compared in Fig. 4. The points in the same vertical line represent the results obtained under the same operating conditions. As can be seen, experimental and theoretical data appreciably differ one 
from the other, which means that equilibrium was not reached during the experimental runs, maybe due to insufficient residence time of the gases in the reactor. Experimental yields of $\mathrm{H}_{2}$ and $\mathrm{CO}$ are clearly below their corresponding theoretical data (up to four and five times lower in the most unfavorable conditions, respectively). The lower the gasification temperature, the greater is the difference between the experimental and the theoretical data. In contrast, experimental yields of $\mathrm{CO}_{2}$ and $\mathrm{CH}_{4}$ are above their corresponding theoretical values. $\mathrm{CH}_{4}$ is mainly produced during the pyrolysis step and is hardly reformed during the subsequent process.

The experimental and theoretical yields of gases have been analyzed statistically by means of ANOVA. In the case of the theoretical results, most of the yields revealed a curvature, so the design was augmented with central composite points in order to determine the evolution of the response variables in the studied ranges and to find out which factor(s) is (are) causing the curvature. Table 5 presents the ANOVA results for both the experimental and the theoretical results.

As can be seen in Table 5, temperature is the most influential factor for the experimental yield of $\mathrm{H}_{2}$. Although this gas is involved in many reactions both as reactant and as product, the temperature rise leads to a global increase in its experimental yield. The same trend for $\mathrm{H}_{2}$ production has usually been reported in the literature $[11,12,27]$. Although to a lesser extent, the $\mathrm{H}_{2}$ experimental yield is also enhanced by increasing the $\mathrm{H}_{2} \mathrm{O} / \mathrm{O}_{2}$ ratio. On the one hand, the increase in the steam presence favors $\mathrm{H}_{2}$ formation $(4,5,6,8)$ and, on the other hand, $\mathrm{H}_{2}$ combustion is mitigated by reducing the proportion of oxygen in the gasification medium. The GR affects the experimental production of $\mathrm{H}_{2}$ in a negative way: $\mathrm{H}_{2}$ consumption outweighs $\mathrm{H}_{2}$ formation when both the ER and the S/B ratio are increased. In contrast to the experimental results, the $\mathrm{H}_{2} \mathrm{O} / \mathrm{O}_{2}$ ratio is the most influential factor for the theoretical 
yield of $\mathrm{H}_{2}$ (Table 5) and it is also the factor responsible for the curvature observed. The influence of the temperature is much less significant in this case and, unlike the experimental results, this factor adversely affects the theoretical production of $\mathrm{H}_{2}$. The WGS reaction (6) may explain this observed trend at equilibrium conditions due to its exothermic nature.

As occurred with the $\mathrm{H}_{2}$ experimental yield, temperature is the most influential factor for the experimental production of $\mathrm{CO}$ (Table 5). Higher temperatures favor the production of $\mathrm{CO}$ through reactions such as steam and dry reforming $(8,9)$, the Boudouard reaction (3) or the water-gas primary reaction (4). However, negligible variations or even the opposite trend in $\mathrm{CO}$ production are found in the literature [10, 11], which reveals the importance of the nature of the biomass and the operating conditions in the evolution of $\mathrm{CO}$ production. Both the GR and the $\mathrm{H}_{2} \mathrm{O} / \mathrm{O}_{2}$ ratio affect the experimental yield of CO in a negative way. When the GR is increased, the higher amount of oxygen fed to the gasifier promotes the oxidation of $\mathrm{CO}$ to $\mathrm{CO}_{2}$ and, in addition, the higher presence of steam favors CO consumption through the WGS reaction. Moreover, the negative effect of the $\mathrm{H}_{2} \mathrm{O} / \mathrm{O}_{2}$ ratio might indicate that the consumption of $\mathrm{CO}$ in the WGS reaction outweighs its combustion process. Both negative effects are significantly intensified at higher temperatures. In contrast to the experimental results, the GR is the most influential factor for the theoretical production of $\mathrm{CO}$ (Table 5) and the $\mathrm{H}_{2} \mathrm{O} / \mathrm{O}_{2}$ ratio shows a positive effect. The three interactions between the factors are significant terms in the theoretical production of $\mathrm{CO}$ : (i) the negative effect of the GR is slightly reduced when working at high temperatures, maybe due to the endothermic nature of the Boudouard reaction (in which $\mathrm{CO}$ is produced); (ii) the positive effect of the temperature is slightly reduced when working at high $\mathrm{H}_{2} \mathrm{O} / \mathrm{O}_{2}$ ratios, since increasing the steam presence shifts the WGS equilibrium towards CO 
consumption; (iii) the negative effect of the GR is intensified when the highest $\mathrm{H}_{2} \mathrm{O} / \mathrm{O}_{2}$ ratio is used as gasification medium.

Regarding the production of $\mathrm{CO}_{2}$, the GR is the most influential factor for both the experimental and the theoretical yields (Table 5). When the GR is increased more oxygen and steam are fed to the gasifier, thus the increased production of $\mathrm{CO}_{2}$ can be attributed to a higher extent of combustion reactions, as well as to other reactions promoted by the presence of steam, such as the WGS reaction (6) or the secondary water-gas reaction (5), in which $\mathrm{CO}_{2}$ is produced. The positive effect of the GR on the experimental yield of $\mathrm{CO}_{2}$ is intensified at higher temperatures and lower $\mathrm{H}_{2} \mathrm{O} / \mathrm{O}_{2}$ ratios. Although to a lesser extent, the increase in the $\mathrm{H}_{2} \mathrm{O} / \mathrm{O}_{2}$ ratio negatively affects the production of $\mathrm{CO}_{2}$. This trend suggests that combustion reactions are the main source of $\mathrm{CO}_{2}$. In contrast to the theoretical results, the experimental yield of $\mathrm{CO}_{2}$ is not significantly influenced by the temperature. Theoretical results show that $\mathrm{CO}_{2}$ and $\mathrm{CO}$ yields are influenced by the same significant factors and interactions, but all of them show opposite effects since $\mathrm{CO}$ production is normally linked with $\mathrm{CO}_{2}$ consumption, and vice versa $(3,6,9)$.

Regarding the experimental production of light hydrocarbons $\left(\mathrm{CH}_{4}\right.$ and $\left.\mathrm{C}_{2} \mathrm{H}_{\mathrm{x}}\right)$, the $\mathrm{H}_{2} \mathrm{O} / \mathrm{O}_{2}$ ratio is the most influential factor for it (Table 5). Increasing the $\mathrm{H}_{2} \mathrm{O} / \mathrm{O}_{2}$ ratio in the gasification medium enhances the production of both $\mathrm{CH}_{4}$ and $\mathrm{C}_{2} \mathrm{H}_{\mathrm{x}}$, thus suggesting that the steam reforming of light hydrocarbons occurs more slowly than its combustion process. The formation of $\mathrm{CH}_{4}$ via the methanation reaction (7) may also be promoted by increasing the $\mathrm{H}_{2} \mathrm{O} / \mathrm{O}_{2}$ ratio due to an increased presence of $\mathrm{H}_{2}$ in the gasification medium. Although to a lesser extent, $\mathrm{CH}_{4}$ production is negatively affected by the increase in the GR, as its combustion and steam reforming reactions are promoted by increasing the ER and the S/B ratio, respectively. This expected effect is 
not observed for the $\mathrm{C}_{2} \mathrm{H}_{\mathrm{x}}$ experimental yield probably because of its large experimental variability. Unlike the results shown by other authors $[12,27]$, the experimental yield of $\mathrm{CH}_{4}$ is found to increase slightly with the temperature, maybe as a result of the thermal cracking of heavier hydrocarbons, while the experimental yield of $\mathrm{C}_{2} \mathrm{H}_{\mathrm{x}}$ follows the opposite trend with temperature. In relation to the theoretical results, the presence of $\mathrm{C}_{2} \mathrm{H}_{\mathrm{x}}$ in the equilibrium gas is practically negligible. $\mathrm{CH}_{4}$ is produced at equilibrium conditions, but its theoretical yield is much lower than its experimental yield. Temperature is the most influential factor for the theoretical yield of $\mathrm{CH}_{4}$ (Table 5). It has a negative effect due to the enhancement of the endothermic reactions in which $\mathrm{CH}_{4}$ is consumed, such as steam and dry reforming $(8,9)$, and the restriction of the methanation reaction (7) due to its exothermic nature. The negative effect of the temperature on the theoretical yield of $\mathrm{CH}_{4}$ is intensified by increasing the $\mathrm{H}_{2} \mathrm{O} / \mathrm{O}_{2}$ ratio and/or decreasing the GR. The temperature also seems to be the factor responsible for the curvature shown by the theoretical yield of $\mathrm{CH}_{4}$.

Lastly, according to the ANOVA results, the experimental production of $\mathrm{H}_{2} \mathrm{~S}$ is favored by increasing both the temperature and the GR, although the effect of the latter is slightly smaller than that of the temperature (Table 5). In contrast to the experimental results, non-significant influences of the studied factors on the theoretical production of $\mathrm{H}_{2} \mathrm{~S}$ have been found within the studied intervals. $\mathrm{H}_{2} \mathrm{~S}$ is the only sulfured-compound considered in the equilibrium gas, thus a constant yield of $\mathrm{H}_{2} \mathrm{~S}$ has been obtained for all the simulated conditions $(25.54 \mathrm{~g} / \mathrm{kg} \mathrm{SS} d a f)$.

\subsection{Lower heating value of the product gas}

The lower heating value of the gas $\left(\mathrm{LHV}_{\text {gas }}\right)$ is calculated as $\Sigma\left(\mathrm{x}_{\mathrm{i}} \cdot \mathrm{LHV}_{\mathrm{i}}\right)$, where $\mathrm{x}_{\mathrm{i}}$ and $\mathrm{LHV}_{\mathrm{i}}$ are the volumetric fraction and the lower heating value $\left(\mathrm{MJ} / \mathrm{m}^{3}{ }_{\mathrm{STP}}\right)$ of each gaseous component, respectively. The LHV of the product gas obtained from the 
sewage sludge gasification ranged between 4.12 and $6.20 \mathrm{MJ} / \mathrm{m}^{3}{ }_{\text {STP }}$, thus this gas can be considered as a low heating value gas. Similar values of $\mathrm{LHV}_{\text {gas }}$ are usually reported in the literature for air gasification or air-steam gasification of other kinds of biomass [5].

As a result of the ANOVA analysis, Table 5 presents the coded coefficients that explain the influence of the factors on the theoretical and experimental gas heating values. As can be seen, the theoretical gas heating values are higher than those obtained experimentally under the same operating conditions. The lower production of $\mathrm{CO}_{2}$ obtained at equilibrium conditions compared to its experimental production leads to a lower dilution effect of the gas from the energy point of view, which outweighs the lower production of light hydrocarbons (gas components with the highest heating value) at equilibrium conditions.

The composition of the gasification medium is the most influential factor for the experimental $\mathrm{LHV}_{\text {gas. }}$. When the $\mathrm{H}_{2} \mathrm{O} / \mathrm{O}_{2}$ ratio is increased, the hydrocarbon content increases and the $\mathrm{CO}_{2}$ content decreases, so both effects contribute to improve the $\mathrm{LHV}_{\text {gas. }}$ The influence of temperature on the experimental $\mathrm{LHV}_{\text {gas }}$ is almost as important as that of the composition of the gasification medium. Although the experimental production of $\mathrm{CO}_{2}$ (in terms of $\mathrm{g} / \mathrm{kg}$ SS daf) is not affected by the temperature, this result is not the same when considering the concentration data, since a clear reduction in the $\mathrm{CO}_{2}$ fraction with temperature is observed (Table 3). The effect of this reduced fraction of $\mathrm{CO}_{2}$ on the gas calorific value is more significant than that of the reduced fraction of light hydrocarbons, so a global positive effect of temperature on the $\mathrm{LHV}_{\text {gas }}$ has been found in this study. In contrast to this, results in the literature usually show a negative effect of the temperature on the $\mathrm{LHV}_{\text {gas }}[12]$, thus showing that the evolution of the gas composition depends on the raw material and the operating conditions. Although its effect is slightly smaller, the GR negatively affects the 
experimental $\mathrm{LHV}_{\text {gas }}$, since both the production of $\mathrm{CO}_{2}$ and the consumption of light hydrocarbons are favored at higher GR.

The theoretical results show that the GR and the $\mathrm{H}_{2} \mathrm{O} / \mathrm{O}_{2}$ ratio have almost the same relative influence on the $\mathrm{LHV}_{\text {gas }}$, whereas the gasification temperature does not affect it significantly (Table 5).

\subsection{Cold gasification efficiency}

The cold gasification efficiency is defined as the ratio between the energy contained in the gas product $\left(\mathrm{m}^{3}{ }_{\text {STPgas }} \cdot \mathrm{LHV}_{\text {gas }}\right)$ and the energy contained in the mass of sewage sludge fed $\left(\mathrm{kg} \mathrm{ss} \cdot \mathrm{LHV}_{\mathrm{SS}}\right)$. Cold gasification efficiency assumes a temperature of $25{ }^{\circ} \mathrm{C}$ of the product gases, so the sensible heat of the gas is not taken into account.

The experimental values of cold gasification efficiency varied between 39 and $66 \%$ and, according to the ANOVA results (Table 5), the temperature and the $\mathrm{H}_{2} \mathrm{O} / \mathrm{O}_{2}$ ratio are the only factors that affect it significantly. Temperature is the most influential factor and its variation from 770 to $850{ }^{\circ} \mathrm{C}$ improves the cold gasification efficiency by $17 \%$. This enhancement is based on the increase of both $\mathrm{LHV}_{\text {gas }}$ and gas production with temperature. Although to a lesser extent, the $\mathrm{H}_{2} \mathrm{O} / \mathrm{O}_{2}$ ratio also affects the experimental gasification efficiency in a positive way, since the $\mathrm{LHV}_{\text {gas }}$ increases with the $\mathrm{H}_{2} \mathrm{O} / \mathrm{O}_{2}$ ratio and the production of gas is not affected by it.

The theoretical cold gasification efficiencies are much higher than the experimental data. Unlike the experimental results, the $\mathrm{H}_{2} \mathrm{O} / \mathrm{O}_{2}$ ratio is the most influential factor for the theoretical cold gasification efficiency, as well as being the factor responsible for the curvature exhibited by the results. As occurred with the theoretical $\mathrm{LHV}_{\text {gas }}$, increasing the GR negatively affects the theoretical cold gasification efficiency, whereas the gasification temperature does not affect it significantly. 


\subsection{Carbon yield to gas phase}

The carbon yield to gas phase is defined as the ratio between the mass of carbon contained in the product gas and the mass of carbon contained in the sewage sludge fed. The conversion of solid carbon during the sewage sludge gasification reached 76-98 wt. $\%$. However, not all the solid carbon leads to the formation of gaseous compounds, as tar is also produced. Therefore, the experimental results of carbon yield to gas phase are slightly lower than the aforementioned range (62-90 wt. \%), whereas a carbon yield to gas phase of $100 \%$ is expected at equilibrium conditions.

According to the ANOVA results (Table 5), carbon yield to gas phase shows a linear response with the factors within the studied intervals. Temperature is the most influential factor, and its variation from 770 to $850{ }^{\circ} \mathrm{C}$ improves the carbon yield to gas phase by 13 wt. \%. The rise in temperature not only favors the heterogeneous reactions between the carbon contained in the sewage sludge and the gas compounds $(3,4,5)$, but also enhances the tar cracking and reforming reactions, so a greater amount of carbon leaves the gasifier as part of the product gas. The effect of the gasification medium is slightly lower than that of the temperature. Carbon yield to gas phase is increased at higher fractions of oxygen and lower fractions of steam, which suggests that carbon oxidation reactions $(1,2)$ take place faster than the heterogeneous water-gas reactions $(4,5)$. To a lesser extent, carbon yield to gas phase is also favored by the GR, since a greater amount of gasifying agent is available to react with the carbon contained in the sewage sludge.

\subsection{Tar composition}

The tar composition was analyzed by gas chromatography (MS/FID GC). Fig. 5 shows a representative chromatogram of the components detected in most of the tar 
samples. Some researchers have divided tar components into several groups based on their molecular weight [28]. A similar classification of tar compounds has been considered in this work in order to analyze the effect of the operating conditions on the fractions of the following families of compounds: heterocyclic aromatics containing $\mathrm{N}$ (including n-methyl-pyridine, benzonitrile, n-methyl-benzonitrile, quinoline, n-methylquinoline, indole, n-phenyl-pyridine, n-naphthalenecarbonitrile, benzoquinoline and 5Hindeno[1,2-b]pyridine); heterocyclic aromatics containing $\mathrm{O}$ (phenol and benzofuran); compounds containing S (2-benzothiophene and propanenitrile, 3,3'-thiobis-); light aromatics with 1 ring (styrene) and light PAH compounds with 2 or 3 rings (indene, naphthalene, n-methyl-naphthalene, biphenyl, biphenylene, fluorene, anthracene and phenantrene).

The areas of the main peaks shown by the GC-FID have been used to compare the composition of the different samples. Therefore, the results presented in this work do not represent actual compositions of the tar samples, but they are useful for analyzing how the factors influence the fraction of each family of compounds. The percentages of the GC-FID-areas obtained for each sample are shown in Table 6. According to the ANOVA results, the temperature and the $\mathrm{H}_{2} \mathrm{O} / \mathrm{O}_{2}$ ratio are the only factors affecting tar composition. Light aromatics and O-aromatics are the most sensitive families to temperature. Their fractions are found to decrease with temperature. Similar results have been reported by other researchers [29], showing that phenolic compounds, paraffines, olefins and alkylated aromatics are easily cracked at high temperatures. The S-compounds fraction has been found to increase with temperature, probably as a result of the aforementioned decrease in the fractions of other compounds.

On the other hand, $\mathrm{N}$-aromatics and light $\mathrm{PAH}$ fractions are the most sensitive families to the $\mathrm{H}_{2} \mathrm{O} / \mathrm{O}_{2}$ ratio. The increase in this ratio leads to a decrease in the fraction 
of light PAHs, thus the presence of steam seems to prevent the polymerization reactions. According to Corella et al. [30], tars generated in gasification with steam are easier to eliminate than tars generated in gasification with air. Tar molecular weight depends on the presence of $\mathrm{H}$ free radicals, which is related to the steam added during gasification [31]. A simultaneous increase in the fraction of $\mathrm{N}$-aromatics was found, but this may only be a consequence of the aforementioned decrease in the light PAH fraction.

\section{Conclusions}

Temperature was found to be the most influential factor for most of the response variables analyzed during sewage sludge gasification. Higher temperatures are favorable for reducing the tar content and improving the gas yield, the gasification efficiency and the carbon yield to gas phase. On the other hand, the gas heating value and the $\mathrm{H}_{2} / \mathrm{CO}$ molar ratio in the product gas are clearly favored by increasing the steam presence and reducing the oxygen presence in the gasification medium. The significant differences between the theoretical and the experimental yields of gases, as well as the differences in the effects of the factors, show how important it is to distinguish between kinetic and thermodynamic control in a gasification process.

\section{Acknowledgements}

The financial support received from the Spanish Ministry of Science and Technology (research project CTQ2010-20137) and from the Spanish Ministry of Education (pre-doctoral grant awarded to N. Gil-Lalaguna, AP2009-3446) is gratefully appreciated.

\section{References}


[1] D. Fytili, A. Zabaniotou, Utilization of sewage sludge in EU application of old and new methods - A review, Renew. Sustain. Energy Rev. 12 (2008) 116-140.

[2] EC. European Commission Council Directive 91/271/EEC of May 21, 1991, on the treatment of urban waste water.

[3] W. Rulkens, Sewage sludge as a biomass resource for the production of energy: Overview and assessment of the various options, Energy Fuel 22 (2008) 9-15.

[4] J. Werther, T. Ogada, Sewage sludge combustion, Prog. Energy Combust. Sci. 25 (1999) 55-116.

[5] P. McKendry, Energy production from biomass (part 3): gasification technologies, Bioresour. Technol. 83 (2002 b) 55-63.

[6] L. Devi, K.J. Ptasinski, F.J.J.G Janssen, A review of the primary measures for tar elimination in biomass gasification processes, Biomass Bioenergy 24 (2003) 125140.

[7] J. Gil, J. Corella, M.P. Aznar, M.A. Caballero, Biomass gasification in atmospheric and bubbling fluidized bed: Effect of the type of gasifying agent on the product distribution, Biomass Bioenergy 17 (1999) 389-403.

[8] G. Schuster, G. Löffler, K. Weigl, H. Hofbauer, Biomass steam gasification - an extensive parametric modeling study, Bioresour. Technol. 77 (2001) 71-79.

[9] M. Campoy, A. Gómez-Barea, F.B. Vidal, P. Ollero, Air-steam gasification of biomass in a fluidised bed: Process optimisation by enriched air, Fuel Process. Technol. 90 (2009) 677-685.

[10] J. Gil, M.P. Aznar, M.A. Caballero, E. Francés, J. Corella, Biomass gasification in fluidized bed at pilot scale with steam-oxygen mixtures. Product distribution for very different operating conditions, Energy Fuel 11 (1997) 1109-1118. 
[11] P.M. Lv, Z.H. Xiong, J. Chang, C.Z. Wu, Y. Chen, J.X. Zhu, An experimental study on biomass air-steam gasification in a fluidized bed, Bioresour. Technol. 95 (2004) 95-101.

[12] F. Pinto, C. Franco, R.N. André, C. Tavares, M. Dias, I. Gulyurtlu, I. Cabrita, Effect of experimental conditions on co-gasification of coal, biomass and plastics wastes with air/steam mixtures in a fluidized bed system, Fuel 82 (2003) 19671976.

[13] M. Dogru, A. Midilli, C.R. Howarth, Gasification of sewage sludge using a throated downdraft gasifier and uncertainty analysis, Fuel Process. Technol. 75 (2002) 55-82

[14] B. Gross, C. Eder, P. Grziwa, J. Horst, K. Kimmerle, Energy recovery from sewage sludge by means of fluidised bed gasification, Waste Manag. 28 (2008) 1819-1826.

[15] J.J. Manyá, J.L. Sánchez, J. Ábrego, A. Gonzalo, J. Arauzo, Influence of gas residence time and air ratio on the air gasification of dried sewage sludge in a bubbling fluidised bed, Fuel 85 (2006) 2027-2033.

[16] A. Midilli, M. Dogru, C.R. Howarth, M.J. Ling, T. Ayhan, Combustible gas production from sewage sludge with a downdraft gasifier, Energy Convers. Manag. $42(2001) 157-172$.

[17] I. Petersen, J. Werther, Experimental investigation and modelling of gasification of sewage sludge in the circulating fluidized bed, Chem. Eng. Process. 44 (2005) 717736.

[18] N. Nipattummakul, I. Ahmed, S. Kerdsuwan, A.K. Gupta, High temperature steam gasification of wastewater sludge, Appl. Energy. 87 (2010) 3729-3734. 
[19] N. Gil-Lalaguna, I. Fonts, G. Gea, M.B. Murillo, L. Lázaro, Reduction of water content in sewage sludge pyrolysis liquid by selective on-line condensation of the vapors, Energy Fuel 24 (2010) 6555-6564.

[20] G. García, E. Cascarosa, J. Ábrego, A. Gonzalo, J.L. Sánchez, Use of different residues for high temperature desulphurization of gasification gas, Chem. Eng. J. 174 (2011) 644-651.

[21] M. Aznar, A.E González, J.J. Manyà, J.L Sánchez, M.B. Murillo, Understanding the effect of the transition period during the air gasification of dried sewage sludge in a fluidized bed reactor, Int. J. Chem. React. Eng. 5 (2007) A18.

[22] P. McKendry, Energy production from biomass (part 1): overview of biomass, Bioresour. Technol. 83 (2002 a) 37-46.

[23] M. Bläsing, M. Müller, Release of alkali metal, sulphur, and chlorine species from high temperature gasification of high- and low-rank coals, Fuel Process. Technol. 106 (2013) 289-294.

[24] P.A. Jensen, F.J. Frandsen, K. Dam-Johansen, B. Sander, Experimental investigation of the transformation and release to gas phase of potassium and chlorine during straw pyrolysis, Energy Fuel 14 (2000) 1280-1285.

[25] J. Corella, J.M. Toledo, G. Molina, Calculation of the conditions to get less than 2 $\mathrm{g} \operatorname{tar} / \mathrm{Nm}^{3}$ in a fluidized bed biomass gasifier, Fuel Process. Technol. 87 (2006) 841-846.

[26] I. Wender, Reactions of synthesis gas, Fuel Process. Technol. 48 (1996) 189-297.

[27] Y.J. Kim, S.H. Lee, S.D. Kim, Coal gasification characteristics in a downer reactor, Fuel 80 (2001) 1915-1922. 
[28] C. Li, K. Suzuki, Tar property, analysis, reforming mechanism and model for biomass gasification - An overview, Renew. Sustain. Energy Rev. 13 (2009) 594604.

[29] A. Ponzio, S. Kalisz, W. Blasiak, Effect of operating conditions on tar and gas composition in high temperature air/steam gasification (HTAG) of plastic containing waste, Fuel Process. Technol. 87 (2006) 223-233.

[30] J. Corella, A. Orio, J.M. Toledo, Biomass gasification with air in a fluidized bed: Exhaustive tar elimination with commercial steam reforming catalysts, Energy Fuel 13 (1999) 702-709.

[31] Y.H. Qin, J. Feng, W.Y. Li, Formation of tar and its characterization during airsteam gasification of sawdust in a fluidized bed reactor, Fuel 89 (2010) 1344-1347. 
Table 1. Proximate and ultimate analyses and heating value of sewage sludge.

\begin{tabular}{lc}
\hline \multicolumn{2}{l}{ Proximate analysis (wt. \%, wet basis) } \\
\hline Moisture & 6.48 \\
Ash & 39.04 \\
Volatiles & 50.09 \\
Fixed carbon & 4.39 \\
\hline \multicolumn{2}{l}{ Ultimate analysis (wt. \%, wet basis) } \\
\hline C & 29.5 \\
H & 4.67 \\
N & 5.27 \\
S & 1.31 \\
\hline HHV (MJ $\left.\cdot \mathrm{kg}^{-1}\right)$ & 12.8 \\
LHV (MJ $\left.\cdot \mathrm{kg}^{-1}\right)$ & 11.8 \\
\hline
\end{tabular}


Table 2. Operating conditions of gasification tests.

\begin{tabular}{lccccccccc}
\hline Experiment number & 1 & 2 & 3 & 4 & 5 & 6 & 7 & 8 & $9,10,11$ \\
\hline Coded values & $1,1,1$ & $-1,1,1$ & $1,-1,1$ & $-1,-1,1$ & $1,1,-1$ & $-1,1,-1$ & $1,-1,-1$ & $-1,-1,-1$ & $0,0,0$ \\
\hline Temperature $\left({ }^{\circ} \mathrm{C}\right)$ & 850 & 770 & 850 & 770 & 850 & 770 & 850 & 770 & 810 \\
\hline $\begin{array}{l}\text { g gasifying agent/g } \\
\text { sewage sludge } d a f\end{array}$ & 1.1 & 1.1 & 0.8 & 0.8 & 1.1 & 1.1 & 0.8 & 0.8 & 0.95 \\
\hline $\begin{array}{l}\mathrm{H}_{2} \mathrm{O} / \mathrm{O}_{2} \text { molar ratio in the } \\
\text { gasifying agent }\end{array}$ & 3 & 3 & 3 & 3 & 1 & 1 & 1 & 1 & 2 \\
\hline \begin{tabular}{l} 
Equivalence ratio (ER) \\
\hline $\begin{array}{l}\text { Steam to biomass daf } \\
\text { mass ratio (S/B) }\end{array}$
\end{tabular} & 0.17 & 0.17 & 0.12 & 0.12 & 0.32 & 0.32 & 0.23 & 0.23 & 0.19 \\
\hline
\end{tabular}


Table 3. Experimental results: product distribution and gas composition.

\begin{tabular}{|c|c|c|c|c|c|c|c|c|c|}
\hline & $1,1,1$ & $-1,1,1$ & $1,-1,1$ & $-1,-1,1$ & $1,1,-1$ & $-1,1,-1$ & $1,-1,-1$ & $-1,-1,-1$ & $0,0,0^{*}$ \\
\hline \multicolumn{10}{|l|}{ Product distribution } \\
\hline $\begin{array}{l}\text { Solid yield } \\
\text { (g solid/100 g SS) }\end{array}$ & 36.8 & 40.1 & 40.1 & 40.7 & 35.6 & 39.2 & 38.4 & 40.0 & $38.2 \pm 0.1$ \\
\hline $\begin{array}{l}\text { Carbon content in the } \\
\text { solid product (wt. \%) }\end{array}$ & 4.56 & 7.61 & 5.66 & 10.20 & 0.51 & 6.20 & 1.00 & 7.09 & $5.89 \pm 0.33$ \\
\hline $\begin{array}{l}\text { Gas yield } \\
\left(\mathrm{m}^{3}{ }_{\mathrm{STP}} / \mathrm{kg} \mathrm{SS}\right)\end{array}$ & 0.72 & 0.51 & 0.65 & 0.53 & 0.72 & 0.52 & 0.71 & 0.49 & $0.61 \pm 0.01$ \\
\hline $\begin{array}{l}\text { Gas yield } \\
\left(\mathrm{m}^{3}{ }_{\mathrm{STP}} / \mathrm{kg} \mathrm{SS} d a f\right)\end{array}$ & 1.32 & 0.94 & 1.20 & 0.97 & 1.32 & 0.96 & 1.30 & 0.89 & $1.13 \pm 0.01$ \\
\hline Tar content $\left(\mathrm{g} / \mathrm{m}_{\mathrm{STP}}^{3}\right)$ & 18.8 & 43.6 & 18.6 & 44.5 & 12.1 & 22.4 & 10.9 & 45.3 & $14.8 \pm 1.4$ \\
\hline \multicolumn{10}{|c|}{ Gas composition (vol. \%, dry basis) } \\
\hline $\mathrm{H}_{2}$ & 24.2 & 18.4 & 25.1 & 20.4 & 18.0 & 11.0 & 20.6 & 13.6 & $19.3 \pm 0.1$ \\
\hline $\mathrm{CO}$ & 8.7 & 5.7 & 10.2 & 7.3 & 11.6 & 7.0 & 14.1 & 7.7 & $9.4 \pm 0.1$ \\
\hline $\mathrm{CO}_{2}$ & 17.1 & 18.6 & 12.6 & 15.5 & 20.7 & 23.8 & 16.0 & 19.8 & $18.1 \pm 0.2$ \\
\hline $\mathrm{CH}_{4}$ & 3.1 & 3.5 & 3.6 & 4.1 & 2.6 & 2.8 & 2.9 & 3.4 & $3.3 \pm 0.1$ \\
\hline $\mathrm{C}_{2} \mathrm{H}_{\mathrm{x}}$ & 1.7 & 2.1 & 1.4 & 2.2 & 1.3 & 1.6 & 1.4 & 2.0 & $1.7 \pm 0.2$ \\
\hline $\mathrm{H}_{2} \mathrm{~S}$ & 0.44 & 0.38 & 0.33 & 0.33 & 0.44 & 0.42 & 0.38 & 0.31 & $0.40 \pm 0.02$ \\
\hline $\mathrm{N}_{2}$ & 44.9 & 51.4 & 46.8 & 50.2 & 45.3 & 53.4 & 44.5 & 53.2 & $47.8 \pm 0.2$ \\
\hline $\mathrm{H}_{2} / \mathrm{CO}$ molar ratio & 2.79 & 3.25 & 2.46 & 2.81 & 1.54 & 1.57 & 1.46 & 1.77 & $2.06 \pm 0.01$ \\
\hline $\mathrm{CO} / \mathrm{CO}_{2}$ molar ratio & 0.51 & 0.30 & 0.81 & 0.47 & 0.56 & 0.29 & 0.88 & 0.39 & $0.52 \pm 0.01$ \\
\hline
\end{tabular}

*mean value \pm standard deviation 
Table 4. Relative influence of the significant factors on the carbon content in the solid product, gas yield, tar content in the gas, and $\mathrm{H}_{2} / \mathrm{CO}$ and $\mathrm{CO} / \mathrm{CO}_{2}$ molar ratios in the product gas.

\begin{tabular}{lccccc}
\hline & $\begin{array}{c}\text { Carbon content in } \\
\text { the solid (wt. \%) }\end{array}$ & $\begin{array}{c}\text { Gas yield } \\
\left(\mathrm{m}^{3} \text { STP } / \mathrm{kg} \mathrm{SS} d a f\right)\end{array}$ & $\begin{array}{c}\text { Tar content in the } \\
\text { gas }\left(\mathrm{g} / \mathrm{m}^{3} \text { STP }\right)\end{array}$ & $\begin{array}{c}\mathrm{H}_{2} / \mathrm{CO} \text { molar } \\
\text { ratio in the gas }\end{array}$ & $\begin{array}{c}\mathrm{CO} / \mathrm{CO}_{2} \text { molar } \\
\text { ratio in the gas }\end{array}$ \\
\hline Average & 5.50 & 1.12 & 27.03 & 2.21 & 0.52 \\
$\mathrm{~T}$ & -2.42 & 0.17 & -11.91 & -0.14 & 0.16 \\
$\mathrm{GR}$ & -0.63 & 0.019 & -2.78 & 0.081 & -0.11 \\
$\mathrm{H} 2 \mathrm{O} / \mathrm{O}_{2}$ & 1.65 & $*$ & 4.35 & 0.62 & $*$ \\
$\mathrm{~T}-\mathrm{GR}$ & $*$ & 0.017 & 3.15 & 0.021 & -0.044 \\
$\mathrm{~T}-\left(\mathrm{H}_{2} \mathrm{O} / \mathrm{O}_{2}\right)$ & 0.53 & -0.024 & $*$ & -0.059 & -0.026 \\
$\mathrm{GR}-\left(\mathrm{H}_{2} \mathrm{O} / \mathrm{O}_{2}\right)$ & $*$ & $*$ & 2.62 & 0.11 & $*$ \\
$\mathrm{~T}-\left(\mathrm{H}_{2} \mathrm{O} / \mathrm{O}_{2}\right)-\mathrm{GR}$ & $*$ & 0.028 & -2.89 & -0.049 & $*$ \\
$\mathrm{Curvature}$ & $*$ & $* *$ & $* *$ & $* *$ & $*$ \\
\hline
\end{tabular}

*non-significant term; ${ }^{* *}$ curvature is significant 
Table 5. Relative influence of the significant factors on the yield of each gaseous compound, the lower heating value of the gas, the cold gasification efficiency and the carbon yield to gas phase (experimental and theoretical results).

\begin{tabular}{|c|c|c|c|c|c|c|c|c|c|}
\hline & \multicolumn{6}{|c|}{ Yield of gaseous compounds ( $\mathrm{g} / \mathrm{kg} \mathrm{SS} d a f)$} & \multirow{2}{*}{$\begin{array}{c}\mathrm{LHV}_{\text {gas }} \\
\left(\mathrm{MJ} / \mathrm{m}_{\text {STP }}^{\text {s }}\right)\end{array}$} & \multirow{2}{*}{$\begin{array}{l}\text { Cold gasification } \\
\text { efficiency }(\%)\end{array}$} & \multirow{2}{*}{$\begin{array}{l}\text { Carbon yield to } \\
\text { gas phase }(\%)\end{array}$} \\
\hline & $\mathrm{H}_{2}$ & $\mathrm{CO}$ & $\mathrm{CO}_{2}$ & $\mathrm{CH}_{4}$ & $\mathrm{C}_{2} \mathrm{H}_{\mathrm{x}}$ & $\mathrm{H}_{2} \mathrm{~S}$ & & & \\
\hline & \multicolumn{9}{|c|}{ Coefficients obtained for the experimental results } \\
\hline Average & 37.03 & 250.10 & 763.42 & 50.23 & 46.13 & 12.66 & 5.49 & 55.12 & 72.48 \\
\hline $\mathrm{T}$ & 9.06 & 78.79 & $*$ & 1.49 & -3.28 & 1.73 & 0.37 & 8.51 & 6.33 \\
\hline GR & -1.37 & -17.51 & 101.57 & -3.13 & $*$ & 1.56 & -0.31 & $*$ & 3.33 \\
\hline $\mathrm{H}_{2} \mathrm{O} / \mathrm{O}_{2}$ & 5.68 & -32.67 & -92.53 & 4.80 & 3.35 & $*$ & 0.40 & 3.47 & -6.07 \\
\hline T-GR & $*$ & -5.03 & 21.59 & $*$ & * & $*$ & $*$ & $*$ & * \\
\hline $\mathrm{T}-\left(\mathrm{H}_{2} \mathrm{O} / \mathrm{O}_{2}\right)$ & $*$ & -21.95 & $*$ & $*$ & $*$ & $*$ & -0.17 & $*$ & $*$ \\
\hline $\mathrm{GR}-\left(\mathrm{H}_{2} \mathrm{O} / \mathrm{O}_{2}\right)$ & $*$ & * & -14.93 & $*$ & $*$ & $*$ & $*$ & $*$ & $*$ \\
\hline $\mathrm{T}-\left(\mathrm{H}_{2} \mathrm{O} / \mathrm{O}_{2}\right)-\mathrm{GR}$ & * & 9.65 & 15.91 & $*$ & $*$ & 0.62 & $*$ & $*$ & $*$ \\
\hline \multirow[t]{2}{*}{ Curvature } & $*$ & $*$ & $*$ & $*$ & $*$ & $*$ & $*$ & $*$ & $*$ \\
\hline & \multicolumn{9}{|c|}{ Coefficients obtained for the theoretical results } \\
\hline Average & 99.53 & 883.23 & 595.21 & 0.60 & -- & 25.54 & 6.56 & 98.47 & 100 \\
\hline $\mathrm{T}$ & -1.19 & 24.54 & -36.44 & -0.76 & -- & $*$ & $*$ & $*$ & $*$ \\
\hline GR & -3.09 & -86.09 & 136.58 & -0.46 & -- & $*$ & -0.35 & -5.64 & $*$ \\
\hline $\mathrm{H}_{2} \mathrm{O} / \mathrm{O}_{2}$ & 14.85 & 36.77 & -58.69 & 0.32 & -- & $*$ & 0.34 & 9.94 & $*$ \\
\hline T-GR & $*$ & 4.96 & -8.85 & 0.38 & -- & $*$ & $*$ & $*$ & $*$ \\
\hline $\mathrm{T}-\left(\mathrm{H}_{2} \mathrm{O} / \mathrm{O}_{2}\right)$ & $*$ & -4.34 & 7.57 & -0.27 & -- & * & $*$ & $*$ & $*$ \\
\hline $\mathrm{GR}-\left(\mathrm{H}_{2} \mathrm{O} / \mathrm{O}_{2}\right)$ & 2.34 & 15.66 & -24.30 & $*$ & -- & $*$ & 0.12 & 2.00 & $*$ \\
\hline $\mathrm{T}-\left(\mathrm{H}_{2} \mathrm{O} / \mathrm{O}_{2}\right)-\mathrm{GR}$ & $*$ & $*$ & $*$ & $*$ & -- & $*$ & $*$ & $*$ & $*$ \\
\hline$\left(\mathrm{H}_{2} \mathrm{O} / \mathrm{O}_{2}\right)^{2}$ & -4.44 & -11.12 & 16.84 & $*$ & -- & $*$ & $*$ & -2.39 & $*$ \\
\hline $\mathrm{T}^{2}$ & $*$ & * & $*$ & 0.42 & -- & $*$ & $*$ & $*$ & $*$ \\
\hline $\mathrm{GR}^{2}$ & * & $*$ & $*$ & $*$ & -- & $*$ & $*$ & $*$ & $*$ \\
\hline
\end{tabular}

*non- significant term 
Table 6. Tar composition (percentage of area in the GC-FID signal of each family of tar compounds).

\begin{tabular}{lccccccccc}
\hline Experiment & $1,1,1$ & $-1,1,1$ & $1,-1,1$ & $-1,-1,1$ & $1,1,-1$ & $-1,1,-1$ & $1,-1,-1$ & $-1,-1,-1$ & $0,0,0 *$ \\
\hline N-aromatics & 74.6 & 68.2 & 57.1 & 68.7 & 46.5 & 44.0 & 44.7 & 60.5 & $50.0 \pm 14.4$ \\
O-aromatics & 3.0 & 7.7 & 0.34 & 7.7 & 0.6 & 2.1 & 1.0 & 6.0 & $2.6 \pm 0.8$ \\
S-compounds & 3.6 & 2.9 & 4.4 & 5.1 & 7.9 & 2.5 & 5.7 & 1.0 & $4.9 \pm 0.1$ \\
Light aromatics (1 ring) & 9.7 & 12.2 & 4.4 & 13.4 & 5.1 & 9.9 & 3.6 & 9.8 & $6.5 \pm 1.8$ \\
$\begin{array}{l}\text { Light PAH compounds } \\
\text { (2-3 rings) }\end{array}$ & 9.1 & 9.1 & 33.8 & 5.14 & 39.9 & 41.5 & 45.0 & 22.7 & $36.0 \pm 8.8$ \\
\hline
\end{tabular}

*mean value \pm standard deviation 


$$
\begin{aligned}
& \text { o } \\
& +3 \\
& 3 \\
& \text { 3. } \\
& 0 \\
& 0 \\
& 0 \\
& 0 \\
& 5 \\
& 5 \\
& 5 \\
& 5 \\
& 0 \\
& 0 \\
& 0 \\
& 0 \\
& 5 \\
& 0 \\
& 0 \\
& 0 \\
& 0 \\
& 0
\end{aligned}
$$

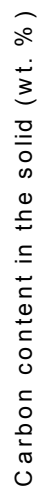

Fig. 1. Carbon content in the solid product (wt. \%). (a) Interaction between temperature and $\mathrm{H}_{2} \mathrm{O} / \mathrm{O}_{2}$ molar ratio $(\mathrm{GR}=0.95)$. (b) Effect of the gasifying ratio $\left(\mathrm{T}=810{ }^{\circ} \mathrm{C}\right.$; $\left.\mathrm{H}_{2} \mathrm{O} / \mathrm{O}_{2}=2\right)$. 
Fig. 2. Gas yield. (a) Interaction between temperature and gasifying ratio $\left(\mathrm{H}_{2} \mathrm{O} / \mathrm{O}_{2}=2\right)$;

(b) Interaction between temperature and $\mathrm{H}_{2} \mathrm{O} / \mathrm{O}_{2}$ molar ratio $(\mathrm{GR}=0.95)$. 
Fig. 3. Tar content in the gas. (a) Interaction between temperature and gasifying ratio $\left(\mathrm{H}_{2} \mathrm{O} / \mathrm{O}_{2}=2\right)$; (b) Interaction between $\mathrm{H}_{2} \mathrm{O} / \mathrm{O}_{2}$ and gasifying ratio $\left(\mathrm{T}=810{ }^{\circ} \mathrm{C}\right)$. 

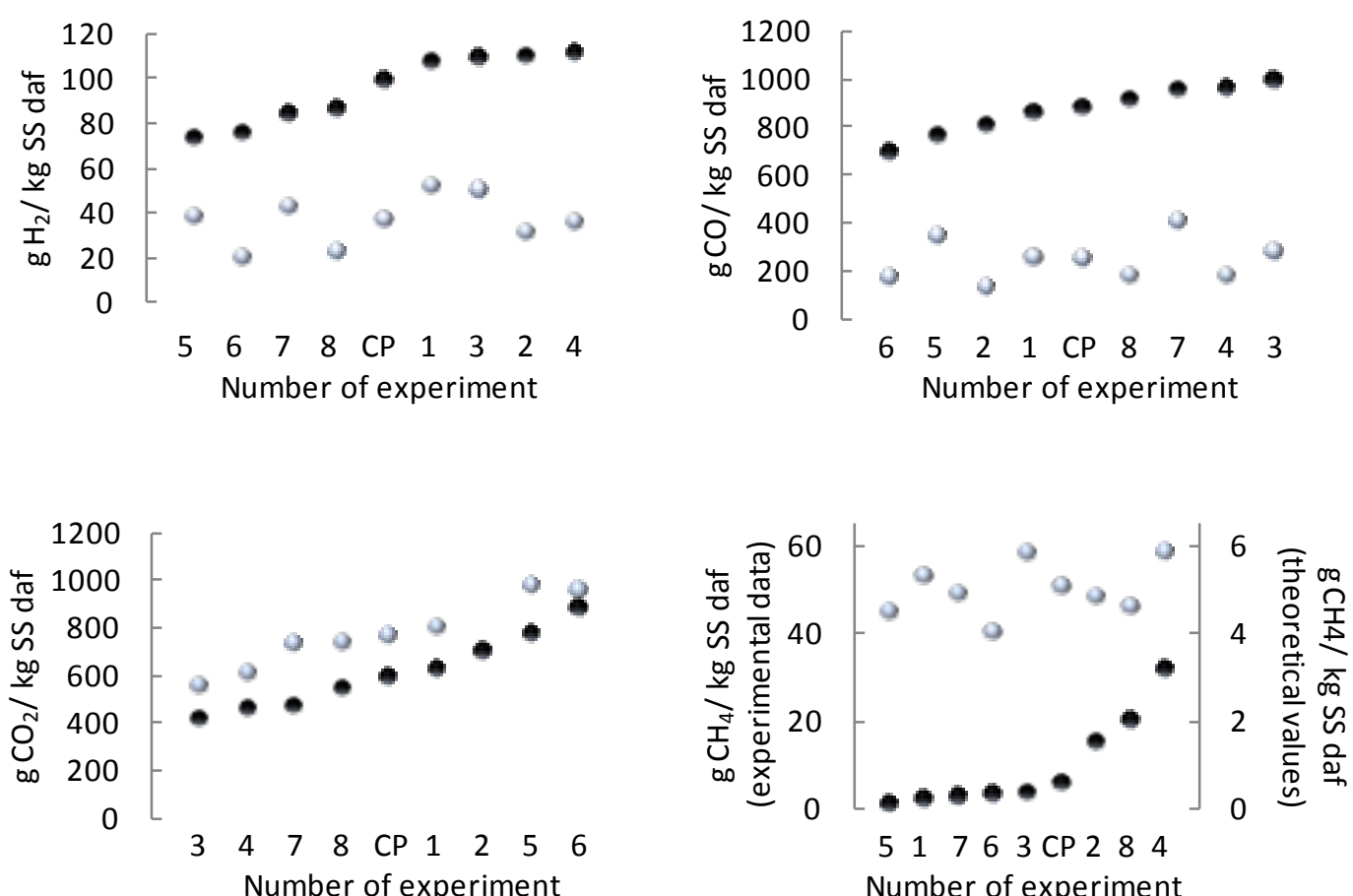

51763 CP 284

Number of experiment

Fig. 4. Theoretical (•) and experimental ( $\bullet$ ) production of $\mathrm{H}_{2}, \mathrm{CO}, \mathrm{CO}_{2}$ and $\mathrm{CH}_{4}$. 


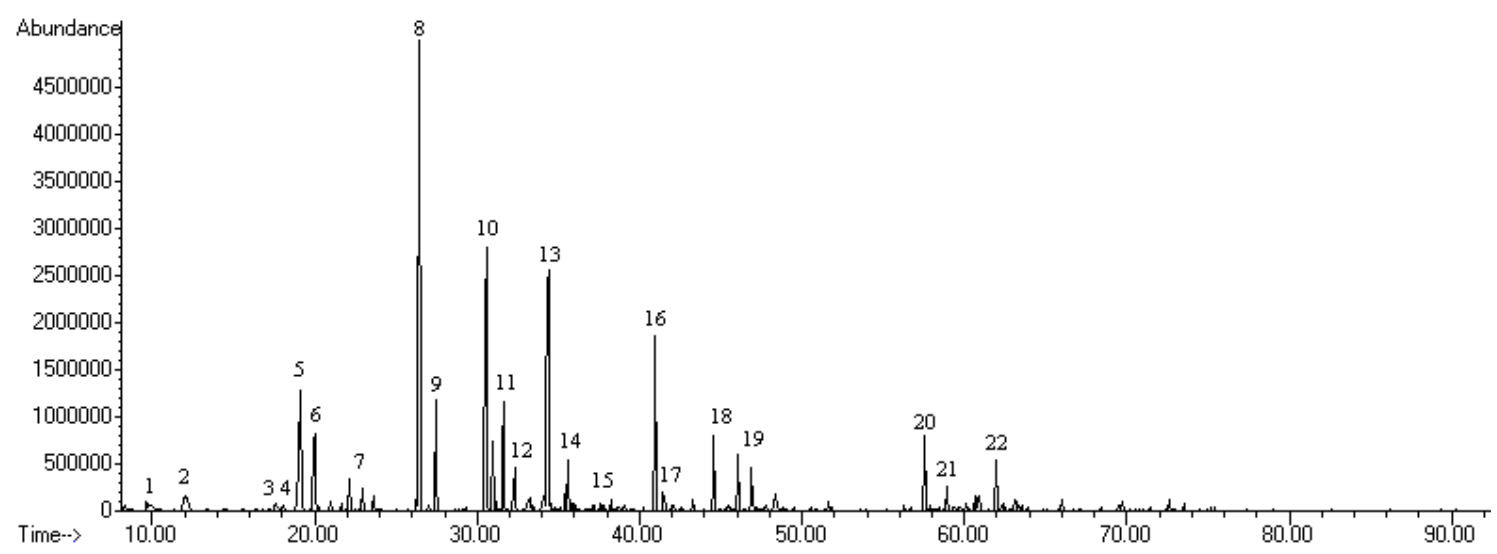

\begin{tabular}{ccc}
\hline 1. Pyridine, n-methyl- (9.6) & 9. 2-Berzothiophene (27.5) & 17. n-Naphthalenecarboritrile (44.5) \\
2. Styrene (11.9) & 10. Quinoline (30.6) & 18. Fluorene (46.9) \\
3. Phenol (17.5) & 11. Naphthalene, n-methyl- (31.0) & 19. Propanenitrile, 3,3'-thiobis- (48.4) \\
4. Benzofuran (17.0) & 12. Quinoline, n-methyl- (33.1) & 20. Anthr acene / Phenantrene (57.6) \\
5. Berzoritrile (19.2) & 13. Indole (34.3) & 21. Benzocuinoline (58.9) \\
6. Indene (20.0) & 14. Biphenyl (35.6) & 22. SH-Indeno[1,2-b]pyridine (61.9) \\
7. Benzoritrile, n-methy1- (22.1) & 15. Biphenyl ene (40.9) & \\
8. Naphthalene (26.4) & 16. Pyridine, n-phenyl- (41.4)
\end{tabular}

Fig. 5. Total ion chromatogram (TIC) of a tar sample obtained at $850{ }^{\circ} \mathrm{C}, \mathrm{GR}=0.8$ and $\mathrm{H}_{2} \mathrm{O} / \mathrm{O}_{2}$ molar ratio $=3$. 